\title{
Low Emission Road Transport Scenarios: An Integrated Assessment of Energy Demand, Air Quality, GHG Emissions, and Costs
}

\author{
Elena De Angelis ${ }^{\circledR}$, Claudio Carnevale, Member, IEEE, Gioele Di Marcoberardino, Enrico Turrini, \\ and Marialuisa Volta, Member, IEEE
}

\begin{abstract}
This article proposes an integrated assessment methodology aimed at supporting decision-makers in design energy production scenarios to power a low emissions traffic fleet. The Multidimensional Air Quality (MAQ) system is used to define and solve a decision problem that selects a set of energy production scenarios minimizing costs, impacts on air quality, and greenhouse gases (GHGs) emissions. This study focuses on the road transport sector, that is responsible for $25 \%$ of European GHGs emissions and $39 \%$ of $\mathrm{NO}_{x}$ emission, a precursor of both $\mathrm{NO}_{2}$ and $\mathrm{PM}_{10}$ concentrations. The electrification of the light vehicle fleet and the use of biomethane to power heavy vehicles are analyzed, estimating the electricity demand increase, exploring different energy production mixes, and assessing the impacts on air quality, costs, and GHGs according to the fuels/sources used to satisfy the energy demand. A case study over Lombardy region, in Northern Italy, is proposed.
\end{abstract}

Note to Practitioners-The study designs a new decision problem implemented and solved through the Multidimensional Air Quality system (MAQ), an integrated assessment modeling tool. Such system integrates a set of databases, models, optimization, and enumeration algorithms. Composing these elements, specific multiobjective decision problems can be designed defining domain (mesoscale, regional, urban), objectives (air quality index, greenhouse gas emissions, costs, population exposure, health impacts), decision variables (technologies, behavioral measures, energy production, fuel switch), and constraints. MAQ system allows the comprehensive analysis of energy, technological, behavioral policies estimating impacts on air quality, human health, GHGs emissions, and costs.

Index Terms-Air quality integrated assessment modeling, decision support systems, energy policies, environmental system analysis, multiobjective decision problems.

\section{NOMENCLATURE}

\section{A. Parameters}

$n_{r} \quad$ Total number of renewable sources.

$n_{n} \quad$ Total number of nonrenewable sources.

$n_{t} \quad$ Total number of renewable and nonrenewable sources.

Manuscript received December 19, 2020; revised March 8, 2021; accepted April 7, 2021. This article was recommended for publication by Editor M. Robba upon evaluation of the reviewers' comments. This work was supported in part by the Hub Biomass Project [ID 1165247, PORFESR 2014-2020, and Regione Lombardia (IT)]. (Corresponding author: Elena De Angelis.)

The authors are with the Department of Mechanical and Industrial Engineering, University of Brescia, 25123 Brescia, Italy (e-mail: e.deangelis@unibs.it). This article has supplementary material provided by the authors and color versions of one or more figures available at https://doi.org/10.1109/TASE.2021.3073241.

Digital Object Identifier 10.1109/TASE.2021.3073241 $\mathrm{lb}_{r j} \quad$ Production lower bounds for each renewable source $j$ [PJ].

$\mathrm{lb}_{n k} \quad$ Production lower bounds for each nonrenewable source $k[\mathrm{PJ}]$.

$\mathrm{re}_{t}^{p} \quad$ Removal efficiency of end-of-pipe technology $t$ for the pollutant $p$.

$\mathrm{ub}_{r j} \quad$ Production upper bounds for each renewable source j [PJ].

$\mathrm{ub}_{n k} \quad$ Production upper bounds for each nonrenewable source $k[\mathrm{PJ}]$.

$\mathrm{uc}_{i} \quad$ Energy policy cost [M€/yr].

$\mathrm{uc}_{t} \quad$ End of pipe measures unit cost $[\mathrm{M} €]$.

$\mathrm{uc}_{u} \quad$ Imported electricity cost [M€/PJ].

$\alpha \quad$ Renewable energy sources share required.

$\varepsilon_{i} \quad$ Share of the total increase in energy demand that can be produced by the source $i$.

$\eta_{z} \quad$ Efficiency of the fuel $z$ internal combustion engine.

$\eta_{e} \quad$ Electric vehicle engine efficiency.

$\eta_{p d, i}$ Power production and distribution efficiency for each source $i$.

\section{B. Variables}

$\Delta \mathrm{al}_{T} \quad$ Variation of activity level in road transport [PJ].

$\mathrm{al}_{i} \quad$ Activity level of each emitting activity in the domain (excluding the electricity production activities) [alu].

$\mathrm{al}_{s, z} \quad$ Activity level of the vehicle class $s$ and fuel $z$ [PJ].

$\mathrm{AQI}_{\mathrm{PM} 10}$ Air quality index: $\mathrm{PM}_{10}$ spatial yearly average concentration $\left[\mu \mathrm{g} / \mathrm{m}^{3}\right]$.

$\mathrm{AQI}_{\mathrm{NO} 2}$ Air quality index: $\mathrm{NO}_{2}$ spatial yearly average concentration $\left[\mu \mathrm{g} / \mathrm{m}^{3}\right]$.

$d \quad$ Electricity demand in the domain [PJ].

$d_{0} \quad$ Base-case electricity demand [PJ].

$\Delta d \quad$ Electricity demand variation $[\mathrm{PJ}]$.

$e \quad$ Emission [t/yr].

$\mathrm{ef}_{i}^{g} \quad$ Emission factor of the fuel $i$ for the greenhouse gas $g$ [kt/alu].

$\mathrm{ef}_{i}^{p} \quad$ Emission factor of the fuel $i$ for the air pollutant $p$ [t/alu].

GHG Greenhouse gases emissions in $\mathrm{CO}_{2}$ equivalent emitted in a year in the domain [kt/yr]. 
$u \quad$ Electricity imported from all areas outside of the domain [PJ].

$\mathrm{nr}_{k} \quad$ Nonrenewable electricity production from source $k[\mathrm{PJ}]$.

$r_{j} \quad$ Renewable electricity production from source $j[\mathrm{PJ}]$.

$\boldsymbol{x} \quad$ Decision variable defined by renewable and nonrenewable sources electricity production [PJ].

$x_{i}^{0} \quad$ Base-case electricity production for the source $i[\mathrm{PJ}]$.

$\Delta x_{i} \quad$ Variation in electricity production from the source $i$.

TC Total policy cost [M€/yr].

$\vartheta_{\mathrm{t}} \quad$ Application rate of $t$-th end-of-pipe measures.

\section{Sets}

$G$ Greenhouse gases $\left\{\mathrm{CO}_{2}, \mathrm{CH}_{4}, \mathrm{~N}_{2} \mathrm{O}, \mathrm{F}_{\text {gas }}\right\}$.

$P$ Air pollutants $\left\{\mathrm{NO}_{x}, \mathrm{NH}_{3}, \mathrm{VOC}, \mathrm{PPM}_{10}, \mathrm{PPM}_{2.5}\right.$, $\left.\mathrm{SO}_{2}\right\}$.

$S \quad$ Set of considered road transport vehicles types.

$T_{i} \quad$ Set of end-of-pipe measures that abate pollutant emitted by the activity $i$.

$Z \quad$ Set of vehicle fuels.

\section{INTRODUCTION}

A MONG the environmental problems that our society has been facing in the last decades, air pollution reduction and climate change control are the most discussed. Even if these two phenomena have different temporal and spatial scales, they are highly interconnected. In fact, climate change impacts on local air quality and, vice versa, air pollution has consequences on climate [1], [2]. Greenhouse gases (GHGs) emissions and air pollution have the same drivers, meaning the human activities whose emissions alter the composition of atmosphere. For example, livestock activities emit ammonia $\left(\mathrm{NH}_{3}\right)$, that is a precursor of secondary particulate matter (PM) and methane $\left(\mathrm{CH}_{4}\right)$, a high potential global warming greenhouse gas. Energy production and transport sector emit both $\mathrm{CO}_{2}$ and various pollutants [mainly nitrogen oxides, sulfur dioxides, volatile organic compounds (VOC), and primary PM (PPM)], $\mathrm{PM}_{10}$ precursors.

Although the last decades are characterized by a gradual decrease of global $\mathrm{CO}_{2}$ emissions in most sectors, road transport is still an exception: in 2016, European traffic GHGs emissions were $26.1 \%$ higher compared to 1990 levels [3]. Furthermore, the European road transport sector accounted in 2017 for the $39 \%$ of total $\mathrm{NO}_{x}$ emission, a precursor of both $\mathrm{NO}_{2}$ and PM. Technological improvements in internal combustion engines (ICEs) (to reach the stricter European emission standard) and on vehicle weight [4] have been applied lately to reduce the traffic environmental impacts. Also, the implementation of behavioral measures, such as lowering speed limits or soft mobility policies [5], for the reduction of fuel consumption or kilometers driven, has been studied in the literature.
But the need for further improvements in air quality and to massively reduce transport $\mathrm{CO}_{2}$ emission leads to study new solutions where electric vehicles (EVs) can play a significant role. One drawback of a massive $\mathrm{EV}$ penetration is the consequent rise in the electric energy demand. Therefore, researchers are focusing their attention on the electricity distribution network management avoiding voltage drops and thermal overloads. Papadopoulos et al. [6] focused on the impacts of EV charging on an urban residential distribution network, comparing deterministic and probabilistic approaches. The assessment of plug-in EVs impacts on the networks is studied considering the charging behavior, based on demographical statistical data [7], or defining approaches to assess distribution network investment and incremental energy losses for different penetration scenarios [8].

This article focuses on a different aspect. In this study, Multidimensional Air Quality (MAQ) system is used to implement and solve a new decision problem where two air quality indexes, GHG emissions, and policy implementation costs are minimized. The decision variable is the electricity production from renewable and nonrenewable sources, constrained in a feasible set, defined by the source availability in the domain and the minimum renewable energy production imposed through legislation. In this study, the implementation of a low emission road traffic policy has been analyzed.

Vehicle fleet electrification can have a large potential for GHGs and pollutants emissions reduction, but it is strongly related to the energy mix used to produce electricity. Lowcarbon energy sources (renewable energy sources (RESs), and nuclear energy) are dominating the electricity mix produced in Europe, with RES accounting for the $29 \%$ of the European electricity production in 2016. This value includes also the use of biomass (19\%), that has a detrimental impact on air quality, because of high emissions of $\mathrm{NO}_{x}, \mathrm{PPM}, \mathrm{VOC}$, and $\mathrm{SO}_{2}$.

The increase in electricity demand, that may be caused by the electrification of transport and industrial sectors, needs to be studied in a climate change-air quality win-win perspective, because the reduction of GHGs emissions and the improvement in air quality need adequate decision support models aiming to help policy makers in the definition of emission abatement programs [9]. Furthermore, the need to reduce the human activity (energy consumption, distance traveled, fuel use) is becoming a key element also in air quality planning, where the only use of end-of-pipe technologies showed to be insufficient [10], [11]. In this context, the integrated assessment of energy and environmental systems, considering costs and impacts on human health and ecosystems, is becoming more relevant [12], [13].

This article is organized as follows. Section II describes the state-of-the-art in terms of energy system models and integrated assessment models (IAMs). The formalization of the decision problem is presented in Section III. Then, the case study set-up and the presentation of the data collected for the Lombardy domain are examined in Section IV. Finally, the results and the conclusions are reported in Sections V and VI, respectively. 


\section{STATE-OF-THE-ART}

\section{A. Energy Policy Decision Support System}

The analysis of energy systems can have different scales and various approaches. Several tools have grown in the past years to support policy makers in designing decarbonization transition. Therefore, various studies reviewed energy systems models and their methodologies [14]-[17] using different types of classification. At national/global scale, the most widely used are the general-purpose energy systems models that can be classified in optimization models and simulation models. Moreover, models focused only on the electricity system and qualitative scenarios-based methods have been applied as a support in energy policy making [14].

The European Commission has historically worked with the simulation model Price-Induced Market Equilibrium System (PRIMES). This tool has been successfully applied to analyze the energy policy for Member States or at EU level [18]-[20]. PRIMES model is composed of submodels, as many as the number of investigated agents, and it determines the equilibrium energy price solving an equilibrium problem with equilibrium constraints (EPEC). EPEC is a mathematical approach aimed at modeling the energy market considering the behaviors of supplier and consumers [21]. The model provides forecasts on how the energy systems may evolve in the future and the energy policy analysis is based on the comparison with the reference projections [22]. Furthermore, the PRIMES model has been coupled with GAINS model (Greenhouse Gas - Air Pollution Interactions and Synergies) [23] to integrate the air quality problem in the analysis, including non- $\mathrm{CO}_{2}$ gases and particulate emissions, therefore, assessing the impacts in terms of air pollutant concentrations and air quality policy implementation costs.

The representation of future energy systems evolution can also be achieved using optimization models based on linear programming problems [14]. One of the most used energy system models is TIAM (TIMES, The Integrated MARKALEFOM System, IAM) [24], developed by the International Energy Agency. It represents the possible evolutions of the energy system at national/global scale over decades. The output scenarios are the result of the minimization of the discounted total system cost [25]. TIMES model was used at national scale in Italy to define the Energy and Climate Integrated National Plan, published in January 2020 (PNIEC, Piano Nazionale Integrato Energia e Clima, [26]). This model created the scenarios for building the future Italian energy strategy in terms of energy consumption reduction, RESs production, supply security, energy price gap, and phase-out of coal plants. The Italian TIMES scenarios were also used to implement the Italian Air Pollution Control plan (PNCIA, [27]) where, from the final energy consumption, the air pollutants emission reductions expected were estimated. Therefore, the air quality impacts were assessed through the Chemical Transport Model (CTM) (Flexible Air quality Regional Model (FARM) [28]).

\section{B. Air Quality IAMs}

The energy system models must be, in general, coupled with air quality IAMs in order to comprehensively assess the policy environmental impacts, not only in terms of $\mathrm{CO}_{2}$ emissions but also in terms of nitrogen oxides, PM, VOC, sulfur dioxides, and ammonia emissions and, therefore, air pollutants concentrations. Also, impacts on human health and ecosystems can be evaluated [12]. The integration is performed by computing the emission scenarios expected from the final energy consumption values given by the energy model.

Air quality IAMs can have two main approaches [12]: scenario analysis and optimization approach.

In the scenario analysis, the IAM computes the impacts of a set of emission reduction measures chosen a priori by an expert or defined using source apportionment techniques [29], [30]. The relation between air pollution precursors emission variation and the air quality indexes, for example, $\mathrm{PM}_{10}$ or $\mathrm{NO}_{2}$ yearly average concentrations, can be described by CTMs, that are physics/chemistry-based models, or by surrogate models. Surrogate models are data-driven models aimed at mimicking the links between emissions and concentrations in a faster computational way. In the optimization approach, the IAM defines a set of efficient measures through cost-effectiveness or multiobjective optimization. In this case, only surrogate models can be used to link emissions and concentrations because CTM is not computationally efficient enough to deal with the number of simulations required [31], [32].

At a national scale, the MESSAGEix model [33], an IAM developed by IIASA, was applied in China to analyze energy consumption and emissions at the refining process level. The study [34] implements a scenario analysis approach where introduces energy efficiency measures in the refining industry processes, studying energy, materials and water consumption, and the air pollutant emissions. In [35] the energy efficiency measures in the cement industry are under investigations applying a framework composed by intensity use curves, a Geographical Information System - based energy model [36], GAINS model [23], AIM/CGE (Asia-Pacific Integrated Model / Computable General Equilibrium), and Health Impact Assessment (HEL) [37].

At regional scale, the multiobjective approach is implemented in RIAT+ (Regional Integrated Assessment Tool plus) [31], applied in several cases study in Europe [38]-[40]. MAQ system was used in [10] to implement a multiobjective optimization where an air quality index (AQI) and the policy costs are minimized. In [10] and [5], the decision variables of the problem are the application rates of emission abatement measures, both end-of-pipe and energy measures.

\section{Methodology}

In this section, the decision problem, formalized through the MAQ system [10], to evaluate energy policies, is presented. MAQ system integrates four modules: 1) a set of databases collecting the information related to the impacts, in terms of cost and emission reductions, for a set of measures; 2) an AQI module, including models able to relate emission reduction to the air quality levels; 3) a module that includes optimization and enumeration algorithms, allowing the solution of the multiobjective decision problem; and 4) an impact module, that defines the impact of the decisions in terms of air quality, 
human/ecosystem health indicators, benefits, and costs. The modularity of the structure allows to implement and solve specific decision problems designed and formalized defining spatial domain, objectives, decision variables, and constraints.

\section{A. Decision Problem}

The decision problem proposed in this work to support energy scenario assessment is formalized as follows:

$$
\begin{aligned}
\underset{x}{\min } f(x) & =\min _{x}\left[\mathrm{AQI}_{\mathrm{PM} 10}(\boldsymbol{x}), \mathrm{AQI}_{\mathrm{NO} 2}(\boldsymbol{x}), \mathrm{TC}(\boldsymbol{x}), \mathrm{GHG}(\boldsymbol{x})\right](1) \\
\text { s.t. } & \varepsilon(\boldsymbol{x})<0 \\
& \eta(\boldsymbol{x})=0
\end{aligned}
$$

where

1) $\mathrm{AQI}_{\mathrm{PM} 10}$ is the $\mathrm{AQI}$ for $\mathrm{PM}_{10}, \mathrm{PM}_{10}$ yearly average spatial mean concentration (Section III-B1).

2) $\mathrm{AQI} \mathrm{NO}_{2}$ is $\mathrm{AQI}$ for $\mathrm{NO}_{2}, \mathrm{NO}_{2}$ yearly average spatial mean concentration (Section III-B1).

3) GHG represents the GHGs emissions in $\mathrm{CO}_{2}$ equivalent emitted in a year in the domain (Section III-B2).

4) TC is the total cost, that includes the energy policy costs, the implementation of new renewable energy plants, imported electricity cost, and the end-of-pipe measures applied to reduce the air pollutant emissions (Section IIIB3).

5) $\boldsymbol{x}$ is the decision variable set that includes the electricity productions from renewable (hydroelectric, photovoltaic (PV), biomass, biofuels, biogas, waste) and nonrenewable sources (natural gas, liquid fossil fuels, and coal) (Section III-C).

6) $\varepsilon$ and $\eta$ constrain $\boldsymbol{x}$ in a feasible set, as defined in Section III-C.

\section{B. Objectives}

1) Air Quality Indexes: The assessment of the air quality impacts depends on the emission variation due to the application of emission abatement policies. They can include energy efficiency abatement measures, that vary energy consumption, and end-of-pipe measures, which reduce the emissions before they are released in atmosphere. Emission variation of pollutant $p$, due to the application of the energy policy, for each electricity source $i$, depends on the increase in electricity production $\Delta x_{i}$

$$
e_{i}^{p}\left(x_{i}\right)=\left(x_{i}^{0}+\Delta x_{i}\right) \cdot \mathrm{ef}_{i}^{p} \cdot\left(1-\sum_{t \in T_{i}} \mathrm{re}_{t}^{p} \cdot \vartheta_{t}\right)
$$

where

- $p \in P=\left\{\mathrm{NO}_{x}, \mathrm{NH}_{3}, \mathrm{VOC}, \mathrm{PPM}_{10}, \mathrm{PPM}_{2.5}, \mathrm{SO}_{2}\right\}$

- $x_{i}^{0}$ is the base-case electricity production for the source $i$

- $\Delta x_{i}$ is the variation in electricity production from the source $i$ due to the energy policy;

- $\mathrm{re}_{t}^{p}$ is the removal efficiency of the end-of-pipe measure $t$ for the pollutant $p$ applied to the power plants;

- $\vartheta_{t}$ is the application rate of $t$-th end-of-pipe measure;

- $T_{i}$ is the set of end-of-pipe measures that abate emissions caused by the activity $i$.
The link between emissions and the $m$-th AQI can be formalized as

$$
\mathrm{AQI}_{m}=h(e(\boldsymbol{x})) \text { with } m=1, \ldots, m_{\text {tot }}
$$

where $m_{\text {tot }}$ is the total number of AQI computed, in this problem $\mathrm{AQI}_{\mathrm{PM} 10}$ and $\mathrm{AQI} \mathrm{I}_{\mathrm{NO} 2}$.

MAQ system includes a set of models linking emissions and AQI. In this work, artificial neural network (ANN)-based statistical models are implemented to compute $h(e(x, \vartheta))$. ANN can describe the nonlinear relationship between precursors emissions (considering also adjacent cells emissions) and AQI. Feed-forward neural structure has been adopted, the models are trained using a set of CTM runs that simulate different precursors emissions variations. This class of models, training, and validation are presented in detail in [10] and [41].

2) GHGs Emissions: greenhouse gases emissions $\mathrm{GHG}_{i}^{g}$ depend on power production from each source $i$

$$
\mathrm{GHG}_{i}^{g}\left(x_{i}\right)=\left(x_{i}^{0}+\Delta x_{i}\right) \cdot \mathrm{ef}_{i}^{g}
$$

where

- $g \in G=\left\{\mathrm{CO}_{2}, \mathrm{CH}_{4}, \mathrm{~N}_{2} \mathrm{O}, \mathrm{F}_{\text {gas }}\right\}$

- $\mathrm{ef}_{i}^{g}$ is the emission factor of the fuel $i$ for the greenhouse gas $g$.

3) Total Cost: The energy policy cost is described considering the following unitary costs:

- energy policy costs: EV, hydroelectric plants revamping, PV plants $\left(\mathrm{uc}_{i}\right)$

- imported electricity cost $\left(\mathrm{uc}_{u}\right)$; and

- cost of the end-of-pipe measures $\left(\mathrm{uc}_{t}\right)$.

The unit costs are expressed in $\mathrm{M} € /$ alu, the Activity Level Unit generally changes for different activities, $x_{i}$ is expressed in petajoule $(\mathrm{PJ})$.

The total cost of the policy scenario is

$$
\mathrm{TC}(\boldsymbol{x})=\sum_{i}\left(x_{i} \cdot \mathrm{uc}_{i}+\mathrm{al}_{i} \cdot \sum_{t \in T_{i}} \mathrm{uc}_{t} \cdot \vartheta_{t}\right)+\mathrm{uc}_{u} \cdot u
$$

where $\mathrm{al}_{i}$ is the Activity Level of each emitting activity in the domain (excluding the electricity production activities).

\section{Decision Variables and Constraints}

The decision variable $\boldsymbol{x}$ of the problem is defined by renewable and nonrenewable sources electricity production, respectively, $\boldsymbol{r}$ and $\mathbf{n r}$

$$
\boldsymbol{x}=\left[\begin{array}{c}
\mathbf{r} \\
\mathbf{n r}
\end{array}\right]
$$

$\boldsymbol{r}$ and $\mathbf{n r}$ are related to the electricity demand $d$

$$
\sum_{j=1}^{n_{r}} r_{j}+\sum_{k=1}^{n_{n}} \mathrm{nr}_{k}+u=d
$$

where

$r_{j}$ is the renewable electricity production from source $j$;

$n_{r}$ is the total number of renewable sources;

$\mathrm{nr}_{k}$ is the nonrenewable fuel electricity production from source $k$; 
$n_{n}$ is the total number of nonrenewable sources;

$u$ is the electricity imported from all areas outside the domain;

$d$ is the electricity demand in the domain, computed as in the following equations:

$$
\begin{aligned}
d & =d_{0}+\Delta d \\
\Delta d & =u+\sum_{i}^{n_{t}} \Delta x_{i} .
\end{aligned}
$$

$d_{0}$ is the base-case electricity demand and $\Delta d$ is the demand increase caused by electrification of the light vehicle fleet. $n_{t}=n_{r}+n_{n}$ is the total number of sources (renewable and nonrenewable) in the domain. $\Delta x_{i}$ is computed for each road transport vehicle class $s$ and fuel $z$

$$
\Delta x_{i}=\frac{\varepsilon_{i} \cdot \Delta \mathrm{al}_{T}}{\eta_{e} \cdot \eta_{p d, i}}
$$

where $\eta_{e}$ and $\eta_{p d}$ are, respectively, the EV engine efficiency and the power production and distribution efficiency, $\varepsilon_{i}$ is the share of the total increase in energy demand that can be produced by the source $i$. The variation of activity level in road transport $\Delta \mathrm{al}_{T}$ can be computed as

$$
\Delta \mathrm{al}_{T}=\sum_{s \in S} \sum_{z \in Z} \mathrm{al}_{s, z} \cdot \eta_{z}
$$

where

- $\mathrm{al}_{s, z}$ is the activity level of the vehicle class $s$ and fuel $z$;

- $\eta_{z}$ is the efficiency of the fuel $z$ ICE;

- $S$ is the set of considered road transport vehicle types;

- $Z$ is the set of vehicle fuels.

The amount of renewable energy produced in a scenario is constrained. First, renewable energy production should be at least what imposed through legislation for a specific year (14) and second the maximum and the minimum energy production possible for each renewable and nonrenewable source is subject to domain-specific limitations (15) and (16). These constraints can be formalized as

$$
\begin{aligned}
\sum_{j=1}^{n_{r}} r_{j} & \geq \alpha \cdot(d-u) \\
\mathrm{lb}_{j}^{r} & \leq r_{j} \leq \mathrm{ub}_{j}^{r} \\
\mathrm{lb}_{k}^{n} & \leq \mathrm{nr}_{k} \leq \mathrm{ub}_{k}^{n}
\end{aligned}
$$

where

- $\alpha$ is the renewable share required by legislation;

- $\mathrm{lb}_{j}^{r}$ and $\mathrm{ub}_{j}^{r}$ are, respectively, the production upper and lower bounds for each renewable source $j$;

- $\mathrm{lb}_{k}^{n}$ and $\mathrm{ub}_{k}^{n}$ are, respectively, the production upper and lower bounds for each nonrenewable source $k$.

Upper and lower bounds depend on the availability of the sources and plants in the domain and fuel-specific legislation limits.

\section{Problem Solving}

The decision problem aims at selecting the not-dominated energy scenario among $N$ feasible scenarios, built distributing the different sources for electricity production (according to the constraints defined in Section III-C). Due to the number of objectives and the complexity of the problem, an enumeration approach [42] is used. A set of feasible solutions are listed: they are computed assigning to $r_{j}$ and $\mathrm{nr}_{k}$ randomly values according to the constraints related to electricity sources production feasibility and legislation. Nondominated scenarios are selected among the feasible solutions.

\section{CAse Study}

Defined the decision problem, it has been implemented and tested for the Lombardy region case study. In this section, the problem constrains are computed defining the electricity production projections and demand. We assess 1) the business as usual (BAU) electricity demand projection for 2030 and 2) different energy scenarios to meet the electricity demand due to the BAU projection and the vehicle fleet electrification.

\section{A. Base-Case Lombardy Energy Scenario: Data and Projections}

The Italian energy plan provides the future energy scenarios according to European Commission 2050 Roadmap. Member states are committed to reduce GHG emission by $85 \%-$ $90 \%$ with respect to 1990 levels. To reach this objective an intermediate step for 2030 has been defined in the "Clean Energy Package for all Europeans," which states that 32\% of final gross European energy consumption will be produced by RES [43]. The Italian plan for energy and climate (PNIEC) sets the RES objective for 2030 at $30 \%$ of final gross energy consumption, divided for electricity production (55\%), thermal energy (33.9\%), and transport (22\%).

In 2018, Lombardy region produced $65.4 \%$ of required electric power demand. The remaining energy demand was covered by the other Italian regions for $4.6 \%$ and imported mainly from France and Switzerland, for 30.0\% [44], [45]. The current energy production in Lombardy is based on fossil fuels (natural gas and coal), solid biomass, waste, solar energy, and hydroelectric plants [45], [46].

The energy production from fossil fuels is estimated from the installed capacity of power plants. In Lombardy, there are 15 combined cycle plants with an average value of equivalent production hours of $1600 \mathrm{hr} / \mathrm{yr}$. Nine of them produce only electric energy with an electric efficiency assumed in $\eta_{\mathrm{E}}=$ 0.55. Six plants produce both thermal and electric energy operating in cogeneration mode $\left(\eta_{\mathrm{E}}=0.50, \eta_{\mathrm{T}}=0.40\right)$. The maximum energy production can be up to $7800 \mathrm{hr} / \mathrm{yr}$ [47], while the reduction presumed for 2030 is $70 \%$ of current hours, $1120 \mathrm{hr} / \mathrm{yr}$, as indicated by the Italian plan for Energy and Climate. Solid biomass and waste are mainly used to produce thermal energy but, in few cases, also electricity is produced in small plants through cogeneration systems. Solid biomass, biogas, biofuels, and waste are classified as bioenergy.

The future of RES in Italy is mainly in the use of solar PV systems, hydroelectric plants, and wind farms. Lombardy is not a suitable location for wind farm implementation due to frequent stagnant air, but it is the Italian region with the highest number of installed PV plants, and it covers the $27.2 \%$ 
TABLE I

Electric Power Production Scenarios Given by the MAQ System Database Values and the PNIEC Projections (PERCENTAGE VARIATION WITH RESPECT TO 2018 AND VALUES IN PJ)

\begin{tabular}{lcccc}
\hline \hline \multicolumn{1}{c}{ Fuel } & $\begin{array}{c}\text { Maximum } \\
\text { Production } \\
{[\mathrm{PJ}]}\end{array}$ & $\begin{array}{c}\text { Basecase } \\
2018\end{array}$ & \multicolumn{2}{c}{2030 scenario } \\
& {$[\mathrm{PJ}]$} & {$[\%]$} & {$[\mathrm{PJ}]$} \\
\hline Natural gas & 759.0 & 136.3 & -30.5 & 94.7 \\
Coal & 0.0 & 0.6 & -100 & 0.0 \\
Oil foss fuels & 10.8 & 10.8 & -30.5 & 7.5 \\
Solid biomass & - & 2.0 & -18.7 & 1.6 \\
Biogas & 214.2 & 13.3 & -18.7 & 10.8 \\
Biofuels & - & 1.3 & -18.7 & 1.0 \\
Waste & - & 4.3 & -18.7 & 3.5 \\
Photovoltaic & 986.7 & 11.4 & +197 & 34.1 \\
Hydroelectric & $64.3 \div 68.8^{\mathrm{a}}$ & 52.7 & +7 & 56.4 \\
\hline \hline
\end{tabular}

${ }^{\text {a }}$ Improvements in the maximum hydroelectricity production can vary according to existing plants revamping $(+14 \%-+22 \%)$.

of the Italian hydroelectric power. The maximum potential hydroelectric energy production is reported by Terna report [45] and in the PNIEC an increase of 7.0\% of the hydroelectric energy consumption is expected nationwide. Moreover, solar PV production can be further improved by installing new PV panels. Considering the regional area available (urbanized area equal to $2464 \mathrm{~km}^{2}$ [48]) and the average solar energy potential, there is still room for improvements in PV implementation [49]. In fact, this is the RES for which the PNIEC expects the maximum increase.

In Table I, the electricity production base-case in the MAQ system has been projected according to Terna e GSE reports. In 2030, taking into account a revamping of existing plants, the increase in hydroelectricity consumption can vary between $14 \%$ and $22 \%$ [50].

Considering the future improvements expected in energy efficiency and the gradual electrification of different activities, the electricity demand will increase by $2.3 \%$. As shown in Table IV the regional production cannot satisfy the increased demand, producing an energy deficit equal to $28.2 \mathrm{PJ}$ that could be covered by increasing the import or further improving production, using RES available in the region that still have potential.

The sources distribution for the base-case scenario and the 2030 scenario are shown in Fig. 1. In 2018 fossil fuels electricity was $66 \%$ of the total electricity produced in the region, in 2030 it will be only the $44 \% .56 \%$ of the production will be produced by RES.

\section{B. Low Emission Road Transport Scenarios}

Electric mobility is growing fast, in 2018 the global electric car fleet exceeded 5.1 million units and the technological advancement are leading also to new vehicle models and cheaper batteries [51]. Different studies have been made to estimate the EV sales projection. Among these the percentage of EVs over the total vehicles sold in 2030 can vary between $5 \%$ and $50 \%$ [52].

In this work, a low emission road transport scenario is assessed: light duty vehicles, cars, and mopeds are shifted to electricity and heavy-duty vehicles (HDVs) are powered

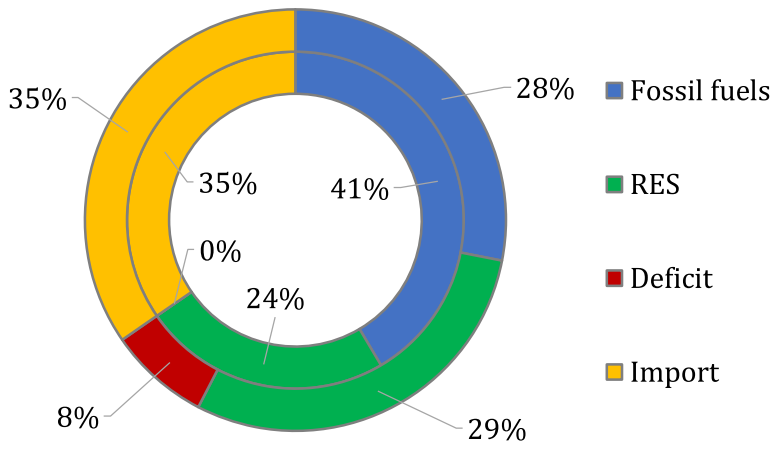

Fig. 1. Electric power production and import in Lombardy in 2018 (inner circle) and projections for 2030 (outer circle) according to data reported by Terna, GSE, and PNIEC.

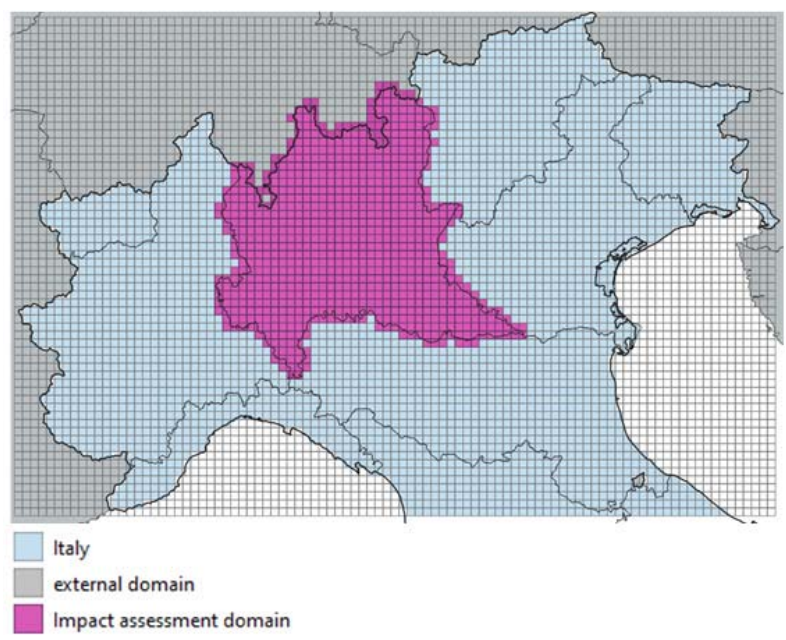

Fig. 2. MAQ model domain, scenarios analysis results are evaluated over Lombardy region (pink cells), the policy is applied on the whole Northern Italy (light blue cells).

TABLE II

HDV B Biomethane Fuel Consumption

\begin{tabular}{lcc}
\hline \hline Fuel & Activity Level [PJ] & $\eta[-]$ \\
\hline Diesel & 66.2 & 0.4 \\
Natural gas & 0.1 & 0.3 \\
\hline Total & 66.4 & \\
\hline $\begin{array}{l}\text { Net energy considering engine } \\
\text { efficiency on biomethane }\end{array}$ & 88.4 & \\
\hline \hline
\end{tabular}

by biomethane. The assessment aims at estimating the maximum benefit achievable in terms of air pollution and GHGs emissions and how the energy mix used to produce electricity can impact on the results. Road transport emissions include nonexhaust emissions due to tires, use of brakes, and road abrasion. These emissions are estimated to not be modified by the electrification of the fleet and the fuel switch in HDV.

The impacts of shifting the whole HDV fleet on biomethane are shown in Table II.

In order to compute the electricity demand due to the fleet electrification, the activity level for each road transport vehicle class and fuel and the corresponding ICE efficiency $\eta$ are needed, as described in (13). The ICE efficiencies considered depend on the fuel and class of vehicles. They are equal to the mean value among all the vehicles belonging to a fuelclass. Moreover, the amount of electricity requested by the 
TABLE III

Energy Demand Due to Vehicle Fleet Electrification (CARs, LDV, AND MOTORCYCLES)

\begin{tabular}{|c|c|c|c|c|}
\hline \multirow[t]{2}{*}{ Fuel } & \multicolumn{3}{|c|}{ Activity Level [PJ] } & \multirow[t]{2}{*}{$\eta[-]$} \\
\hline & Cars & LDV & Mopeds & \\
\hline Diesel & 97.5 & 9.8 & 0.0 & 0.4 \\
\hline Gasoline & 27.9 & 0.6 & 0.7 & 0.3 \\
\hline LPG & 20.6 & 0.0 & 0.0 & 0.3 \\
\hline Natural gas & 3.7 & 0.2 & 0.0 & 0.3 \\
\hline Gross electric fleet energy & & 160.9 & & 0.9 \\
\hline $\begin{array}{l}\text { Net energy considering } \\
\text { engine efficiency (ICE and } \\
\text { electric) }\end{array}$ & \multicolumn{4}{|c|}{65.6} \\
\hline $\begin{array}{l}\text { Energy demand considering } \\
46 \% \text { electricity production } \\
\text { and distribution efficiency }\end{array}$ & \multicolumn{4}{|c|}{142.6} \\
\hline
\end{tabular}

fleet must consider the electric engine efficiency (higher than ICE efficiency) and the losses due to electricity production and distribution. This latter value is given at the national level by the Italian Energy Authority (ARERA). It defines the conversion factor of electric energy in primary energy, therefore, the production and distribution efficiency index is equal to $46 \%$. The electricity demand has been estimated for the Lombardy region (142.6 PJ) processing data from vehicle fleet database included in the MAQ system (Table III).

In Table IV, the final electricity demand (506.4 PJ) is computed adding the 2030 energy demand projection (363.8 PJ) and the increase due to vehicle fleet electrification (142.6 PJ).

\section{Scenarios Design and Implementation}

The electricity deficit of $121.6 \mathrm{PJ}$ is distributed among the $i$ different energy sources, varying $\varepsilon_{i}$ according to the regional energy production upper and lower bounds [see (15) and (16)]. The lower bound is the value defined by the PNIEC projection and the upper bound depends on the production feasibility of each power source, computed according to data reported in Section III-A.

According to the enumeration approach defined in Section III-D, 22 scenarios for Lombardy region (see Fig. 2) are identified randomly varying the control variables, meaning the sources electricity production, within the feasible set (detailed values for all scenarios are reported in the supplementary material):

1) 13 scenarios respect the $55 \%-45 \%$ percentage distribution between RES and fossil fuels, Italian objective for 2030;

2) in five scenarios there is an increase in RES share, up to a $80 \%-20 \%$ ratio; and

3) four scenarios have the ambitious goal of $100 \%$ RES production.

In Fig. 3, the activity level distribution of the 22 scenarios is presented for the different sources. There is no evident variation in fossil fuels: coal is always 0 , as expected past 2025 due to coal plants decommissioning.

The RESs have still room for improvement, except hydroelectric, where, according to data collected, only a maximum increase of 12.4 PJ is feasible.

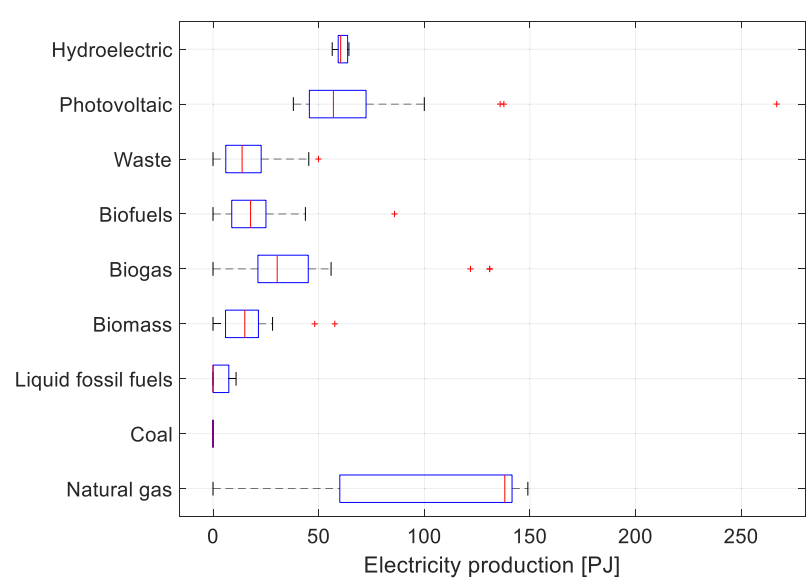

Fig. 3. Electricity production distribution in PJ over the sources available in the region.

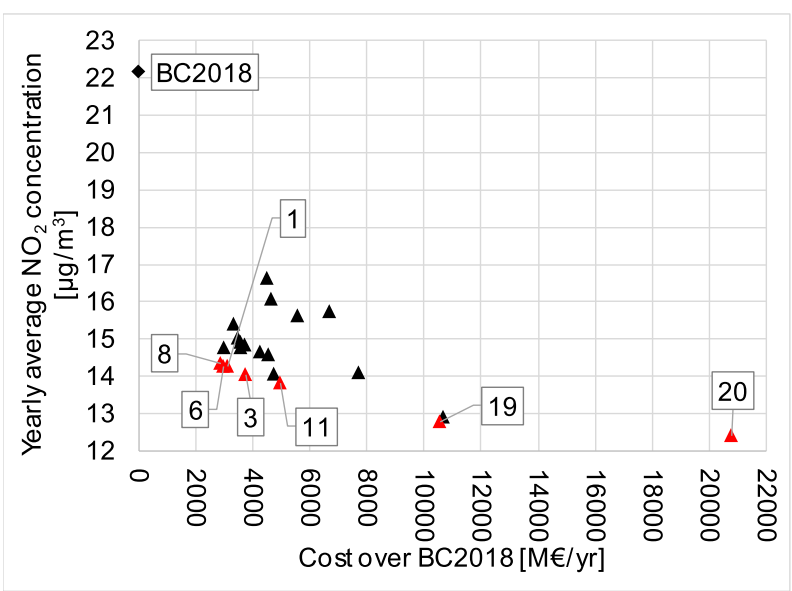

Fig. 4. Objective space 1: Cost $-\mathrm{NO}_{2}$ concentrations.

TABLE IV

Regional Electric EnERgy Production, Demand AND IMPORT

\begin{tabular}{lccc}
\hline \hline \multicolumn{1}{c}{ Fuel } & Basecase 2018 & Projection 2030 & $\begin{array}{c}\text { Low emission } \\
\text { traffic scenario } \\
2030\end{array}$ \\
\hline Energy demand & 355.7 & $363.8(+2.3 \%)$ & 506.4 \\
Production & 232.6 & 209.6 & 209.6 \\
Import & 123.1 & 125.9 & 175.2 \\
Production+import & 355.7 & 335.6 & 384.8 \\
Deficit & 0 & 28.2 & 121.6 \\
\hline \hline
\end{tabular}

\section{REsults AND Discussion}

Defined all the decision problem elements, MAQ model is applied to the simulation domain, to assess the cost and the impact on air quality and GHGs emissions of selected scenarios.

\section{A. Electricity Production Scenarios}

The 22 scenarios assessed with MAQ are plotted in the three objective spaces; scenarios highlighted in red are the nondominated solutions in each objective space.

1) Cost - mean yearly $\mathrm{NO} 2$ concentrations (Fig. 4): scenarios 1, 3, 6, 8, 11, 19 and 20 are nondominated

2) Cost - mean yearly $\mathrm{PM}_{10}$ concentrations (Fig. 5): scenarios $1,3,6,8,19$, and 20 are nondominated. 


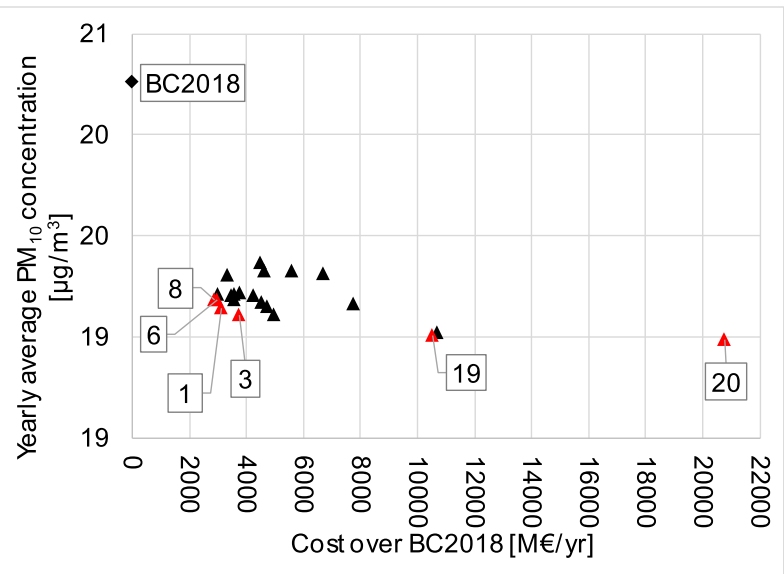

Fig. 5. Objective space 2: Cost $-\mathrm{PM}_{10}$ concentrations.

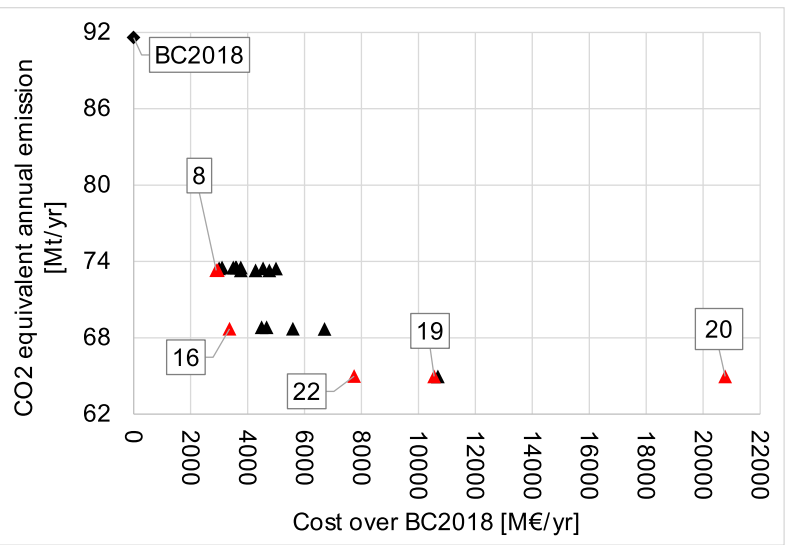

Fig. 6. Objective space 3: Cost $-\mathrm{CO}_{2}$ equivalent emissions.

3) Cost - mean yearly $\mathrm{CO}_{2 \mathrm{eq}}$ emissions (Fig. 6): scenarios $8,16,19,20$, and 22 are nondominated.

Scenarios 1, 3, and 6 are efficient in the objective space 1 and 2 but they are dominated in objective space 3 . Scenario 22 is efficient accordingly to $\mathrm{CO}_{2}$ and cost but is dominated in air quality objective spaces.

Not dominated scenarios for all objectives are 8, 19, and 20. The selected scenarios have different activity levels distribution over the electricity production sources, scenario 8 has the minimum electricity RES production objective for 2030 (55\%), while in scenarios 19 and 20 production is totally from RES. Detailed distribution of the power production is shown in Fig. 7.

\section{B. Emissions}

In Table $\mathrm{V}$, the percentage emission reductions with respect to the base-case scenario are reported. The main reductions are in $\mathrm{NO}_{x}$ and $\mathrm{SO}_{2} . \mathrm{NO}_{x}$ is emitted from fuel combustion, therefore, it is caused by energy production plants and, mainly, by vehicles ICEs. $\mathrm{SO}_{2}$ is emitted by power production plants, combustion in industries (a sector that is not under study in this article) and, to a lesser extent, by road transport. The vehicle fleet electrification and the biomethane use in HDV abate the road transport sector $\mathrm{NO}_{x}$ emission by $95.9 \%$ and $\mathrm{SO}_{2}$ emission by $100 \%$. The total emission reductions depend on the electricity production sources used. In scenarios 19 and 20,

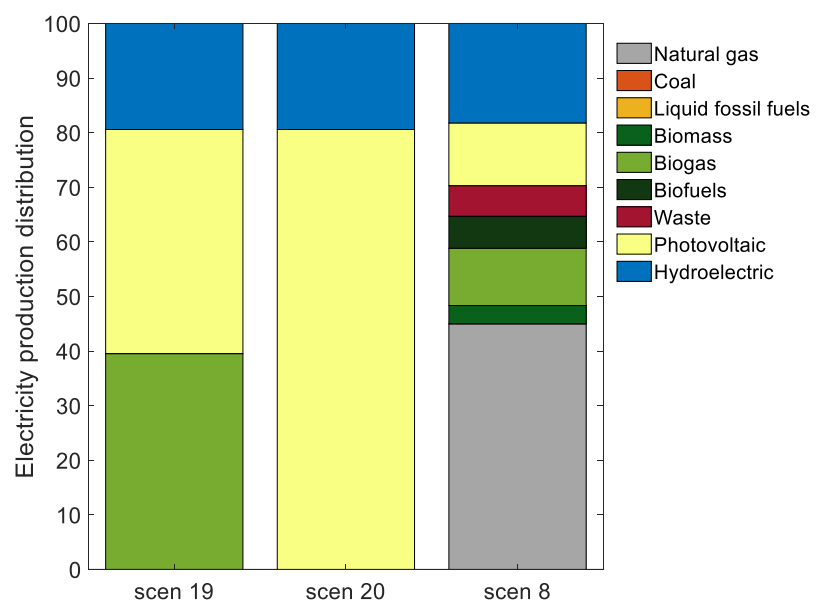

Fig. 7. Percentage electricity production distribution over the sources for the selected scenarios.

TABLE V

Air Pollution Precursors Percentage Emission Reduction With

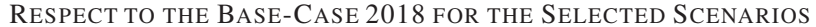

\begin{tabular}{ccccccc}
\hline \hline Scenario & $\mathrm{NO}_{\mathrm{x}}$ & $\mathrm{VOC}$ & $\mathrm{NH}_{3}$ & $\mathrm{PPM}_{10}$ & $\mathrm{PPM}_{2.5}$ & $\mathrm{SO}_{2}$ \\
\hline scen 8 & $-46.8 \%$ & $-1.8 \%$ & $-0.5 \%$ & $-4.7 \%$ & $-5.8 \%$ & $-15.2 \%$ \\
scen 19 & $-53.4 \%$ & $-3.4 \%$ & $-0.6 \%$ & $-6.1 \%$ & $-7.3 \%$ & $-21.8 \%$ \\
scen 20 & $-55.0 \%$ & $-3.4 \%$ & $-0.6 \%$ & $-6.1 \%$ & $-7.4 \%$ & $-22.0 \%$ \\
\hline
\end{tabular}

TABLE VI

Cost Over the Base-CASe 2018 and Objectives Reduction With RESPECT TO THE BASE CASE FOR THE SELECTED SCENARIOS

\begin{tabular}{lcccc}
\hline \hline Scenario & Cost over $\mathrm{BC}[\mathrm{M€} / \mathrm{yr}]$ & $\Delta \mathrm{PM}_{10}$ & $\Delta \mathrm{NO}_{2}$ & $\Delta \mathrm{CO}_{2}$ \\
\hline scen 8 & 2905 & $-5.3 \%$ & $-35.3 \%$ & $-20.0 \%$ \\
scen 19 & 10550 & $-6.2 \%$ & $-42.4 \%$ & $-29.1 \%$ \\
scen 20 & 20773 & $-6.3 \%$ & $-44.0 \%$ & $-29.1 \%$ \\
\hline \hline
\end{tabular}

the abatement of $\mathrm{NO}_{x}$ and $\mathrm{SO}_{2}$ is maximum, because the electricity is produced mainly with "clean" RES, hydroelectric and PV, that do not have direct pollutant emissions; furthermore, biogas and natural gas have a low $\mathrm{NO}_{x}$ emission factor $\left(0.03-0.06 \mathrm{kt} / \mathrm{PJ}\right.$ in modern power plants). In scenario $8, \mathrm{NO}_{x}$ emissions strictly depend on the use of biofuels, biomass, and waste.

\section{Air Quality and GHG Emissions}

Air quality indexes, GHG, and costs are reported in Table VI, expressed, respectively, in percentage variation with respect to the base case and cost over the base case in $\mathrm{M} € / \mathrm{yr}$. Air quality impacts are significant for $\mathrm{NO}_{2}$ concentrations, this is related to the abatement of $\mathrm{NO}_{x}$ emissions. The best result is obtained for scenario 20 , with a $44.0 \%$ reduction corresponding to a maximum spatial average reduction of $9.8 \mu \mathrm{g} / \mathrm{m}^{3}$.

$\mathrm{PM}_{10}$ reductions vary between $5.3 \%$ and $6.3 \%$, meaning a maximum reduction of $1.3 \mu \mathrm{g} / \mathrm{m}^{3} . \mathrm{PM}_{10}$ concentrations impacts are negligible, compared to $\mathrm{NO}_{2}$. The concentrations over the domain are mainly due to PPM ( $\mathrm{PPM}_{10}$ and $\left.\mathrm{PPM}_{2.5}\right)$ emitted by residential heating sources, and to secondary PM 


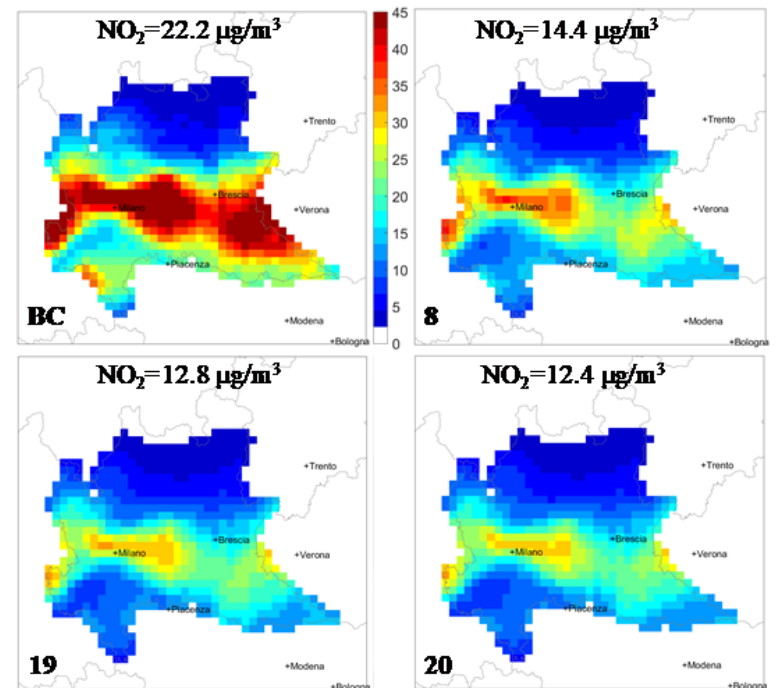

Fig. 8. $\mathrm{NO}_{2}$ average concentration in $\mu \mathrm{g} / \mathrm{m}^{3}$ estimated for the efficient scenarios and the base-case 2018 (BC).

formation caused by $\mathrm{NO}_{x}, \mathrm{VOC}, \mathrm{NH}_{3}$, and $\mathrm{SO}_{2}$ emissions. While $\mathrm{NO}_{x}$ and $\mathrm{SO}_{2}$ emission are considerably reduced, VOC and $\mathrm{NH}_{3}$ emission have negligible reductions in the scenarios analyzed.

Scenario 8 reduces $\mathrm{CO}_{2}$ equivalent emissions by $20 \%$, while scenarios 19 and 20 increase the GHG abatement to $29.1 \%$, but the policy implementation cost in these two scenarios is one order of magnitude higher. The use of RES already implemented in the domain, such as biomass and biofuels, allows to reduce GHGs emissions at a moderate cost.

In scenario 8, natural gas is used for the $45 \%$, RES is mainly solar, hydroelectric, and biomethane. These sources have low emission factors for air pollution precursors, but natural gas has higher $\mathrm{CO}_{2}$ emission factors, equal to $55.8 \mathrm{kt} / \mathrm{PJ}$.

In Fig. 8, concentration maps over the domain are reported for $\mathrm{NO}_{2}$. The fleet electrification allows a diffuse reduction of concentration exposure, that is critical at the base case, especially in the highly urbanized area Milan-Bergamo-Brescia. Even if scenario 8 still presents some critical hotspots, especially in the Milan metropolitan area and the western border, the policy allows to contain the average annual concentrations below the European limit value, $40 \mu \mathrm{g} / \mathrm{m}^{3}$, in the most part of the domain.

\section{CONCLUSION}

In this study, an integrated assessment analysis has been performed to support decision-makers in evaluating energy scenarios to power the electrification of traffic fleet and the fuel switch to biomethane of HDV fleet, minimizing costs, air pollution $\left(\mathrm{NO}_{2}\right.$ and $\mathrm{PM}_{10}$ concentrations), and GHG emissions. The decision problem has been formalized and solved through the MAQ system.

The case study presented can help in the evaluation of costs and benefits, through a quantitative estimation of the impacts on air quality, GHG emissions, and costs taking into account the economic, demographic, and technological projection reported in the Energy and Climate National Plan. Furthermore, the results suggest what are the best energy mixes possible and which are the RESs to invest on.

The results show, as expected, that the reduction of ICEs fuel consumption of the current fleet has a great impact on $\mathrm{NO}_{2}$ concentrations. The $\mathrm{NO}_{2}$ annual average concentration is estimated to decrease over the whole domain (reductions between $35.3 \%$, scen 8 , and $44.0 \%$, scen 20 ). $\mathrm{PM}_{10}$ concentrations in Northern Italy, often discussed because of the chronical exceedances of the European limit values, are minimally impacted by the scenarios analyzed (the maximum reduction achievable is $6.3 \%$ ).

Furthermore, the case study focuses on alternative electric power sources and how the energy mix used can change the impacts on air quality and $\mathrm{CO}_{2}$ emissions. The use of RESs is still limited but it is growing fast, and clear paths are defined by European and National regulation. RES includes biomass, waste, and biofuels, emitting less $\mathrm{CO}_{2}$ with respect to natural gas but more PPM, VOC, and $\mathrm{SO}_{2}$; therefore, negative impacts on air quality can arise from their application. On the other hand, the use of fossil natural gas has a detrimental impact on GHG emission but a higher effect on air pollution concentration reduction. "Cleaner" solution, such as PV panels and hydroelectric plants have limitations due to the implementation cost (for the PV panels) and revamping feasibility and costs (hydroelectric plants).

In the scenarios analyzed, the $\mathrm{CO}_{2}$ equivalent reduction varies between $20.0 \%$ and $29.1 \%$ and the corresponding policy implementation costs increase by one order of magnitude. If we consider, for example, the use of biogas, PV, and hydroelectricity (scenario 19) compared to the use of only PV panels and hydroelectric plants (scenario 20), the results show how including biogas can have a small detrimental impact on air quality $\left(+0.3 \mu \mathrm{g} / \mathrm{m}^{3}\right.$ in $\mathrm{NO}_{2}$ concentrations, negligible for $\mathrm{PM}_{10}$ ) but an increase in costs of $97 \%$.

The work stresses the role of Integrated Assessment Modeling tools in the design and implementation of decision problems for complex systems control, when policies impact on different processes (air quality and climate change) and dimensions (economy, technological innovation, human and ecosystem health).

\section{REFERENCES}

[1] E. von Schneidemesser et al., "Chemistry and the linkages between air quality and climate change," Chem. Rev., vol. 115, pp. 3856-3897, May 2015.

[2] C. Carnevale et al., "Impact of pollutant emission reductions on summertime aerosol feedbacks: A case study over the PO valley," Atmos. Environ., vol. 122, pp. 41-57, Dec. 2015.

[3] Progress of EU Transport Sector Towards its Environment and Climate Objectives, Eur. Environ. Agency, København, Denmark, 2018, pp. $1-13$.

[4] S. Cecchel et al., "Impact of reduced mass of light commercial vehicles on fuel consumption, $\mathrm{CO}_{2}$ emissions, air quality, and socio-economic costs," Sci. Total Environ., vols. 613-614, pp. 409-417, Feb. 2018.

[5] C. Carnevale, E. D. Angelis, G. Finzi, E. Turrini, and M. Volta, "Evaluating economic and health impacts of active mobility through an integrated assessment model," IFAC-PapersOnLine, vol. 51, no. 5, pp. 49-54, 2018.

[6] P. Papadopoulos, S. Skarvelis-Kazakos, I. Grau, L. M. Cipcigan, and N. Jenkins, "Electric vehicles' impact on British distribution networks," IET Electr. Syst. Transp., vol. 2, no. 3, p. 91, 2012.

[7] D. Steen, L. A. Tuan, O. Carlson, and L. Bertling, "Assessment of electric vehicle charging scenarios based on demographical data," IEEE Trans. Smart Grid, vol. 3, no. 3, pp. 1457-1468, Sep. 2012. 
[8] L. P. Fernández, T. G. S. Román, R. Cossent, C. M. Domingo, and P. Frías, "Assessment of the impact of plug-in electric vehicles on distribution networks," IEEE Trans. Power Syst., vol. 26, no. 1, pp. 206-213, Feb. 2011.

[9] M. Maione et al., "Air quality and climate change: Designing new win-win policies for Europe," Environ. Sci. Policy, vol. 65, pp. 48-57, Nov. 2016.

[10] E. Turrini, C. Carnevale, G. Finzi, and M. Volta, "A non-linear optimization programming model for air quality planning including cobenefits for GHG emissions," Sci. Total Environ., vol. 621, pp. 980-989, Apr. 2018.

[11] I. D'Elia, M. Bencardino, L. Ciancarella, M. Contaldi, and G. Vialetto, "Technical and non-technical measures for air pollution emission reduction: The integrated assessment of the regional air quality management plans through the Italian national model," Atmos. Environ., vol. 43, no. 39, pp. 6182-6189, Dec. 2009.

[12] G. Guariso, M. Maione, and M. Volta, "A decision framework for integrated assessment modelling of air quality at regional and local scale," Environ. Sci. Policy, vol. 65, pp. 3-12, Nov. 2016.

[13] P. Viaene et al., "Air quality integrated assessment modelling in the context of EU policy: A way forward," Environ. Sci. Policy, vol. 65, pp. 22-28, Nov. 2016

[14] S. Pfenninger, A. Hawkes, and J. Keirstead, "Energy systems modeling for twenty-first century energy challenges," Renew. Sustain. Energy Rev., vol. 33, pp. 74-86, May 2014.

[15] D. Scamman et al., "Heat decarbonisation modelling approaches in the UK: An energy system architecture perspective," Energies, vol. 13, no. 8, p. 1869 , Apr. 2020.

[16] H.-K. Ringkjøb, P. M. Haugan, and I. M. Solbrekke, "A review of modelling tools for energy and electricity systems with large shares of variable renewables," Renew. Sustain. Energy Rev., vol. 96, pp. 440-459, Nov. 2018.

[17] A. M. Foley, B. P. Ó Gallachóir, J. Hur, R. Baldick, and E. J. McKeogh, "A strategic review of electricity systems models," Energy, vol. 35, no. 12 , pp. $4522-4530$, Dec. 2010

[18] P. Capros, N. Tasios, A. De Vita, L. Mantzos, and L. Paroussos, "Modelbased analysis of decarbonising the EU economy in the time horizon to 2050," Energy Strategy Rev., vol. 1, no. 2, pp. 76-84, Sep. 2012

[19] P. Capros et al., "Outlook of the EU energy system up to 2050: The case of scenarios prepared for European Commission's "clean energy for all Europeans' package using the PRIMES model," Energy Strategy Rev., vol. 22, pp. 255-263, Nov. 2018.

[20] P. Siskos, G. Zazias, A. Petropoulos, S. Evangelopoulou, and P. Capros, "Implications of delaying transport decarbonisation in the EU: A systems analysis using the PRIMES model," Energy Policy, vol. 121, pp. 48-60, Oct. 2018.

[21] D. Ralph and Y. Smeers, "EPECs as models for electricity markets," in Proc. IEEE PES Power Syst. Conf. Expos., Nov. 2006, pp. 74-80.

[22] PRIMES MODEL 2013-2014 Detailed Model Description, E3MLab/ICCS, Athens, Greece, 2014.

[23] M. Amann et al., "Cost-effective control of air quality and greenhouse gases in Europe: Modeling and policy applications," Environ. Model. Softw., vol. 26, no. 12, pp. 1489-1501, Dec. 2011.

[24] R. Loulou and M. Labriet, "ETSAP-TIAM: The TIMES integrated assessment model part I: Model structure," Comput. Manage. Sci., vol. 5 , nos. 1-2, pp. 7-40, Feb. 2008.

[25] R. Loulou, "ETSAP-TIAM: The TIMES integrated assessment model. Part II: Mathematical formulation," Comput. Manage. Sci., vol. 5, nos. 1-2, pp. 41-66, Feb. 2008.

[26] Piano Nazionale Integrato per l'Energia e il Clima, Ministry Econ. Develop., Rome, Italy, 2019.

[27] Programma Nazionale di Controllo dell'Inquinamento Atmosferico, MATTM, Rome, Italy, 2019.

[28] C. Silibello et al., "Modelling of $\mathrm{PM}_{10}$ concentrations over Milano urban area using two aerosol modules," Environ. Model. Softw., vol. 23, no. 3, pp. 333-343, Mar. 2008.

[29] C. Carnevale, E. D. Angelis, G. Finzi, A. Pederzoli, E. Turrini, and M. Volta, "A non linear model approach to define priority for air quality control," IFAC-PapersOnLine, vol. 51, no. 13, pp. 210-215, 2018.

[30] C. A. Belis et al., "Evaluation of receptor and chemical transport models for PM10 source apportionment," Atmos. Environ. X, vol. 5, Jan. 2020, doi: 10.1016/j.aeaoa.2019.100053.

[31] C. Carnevale et al., "An integrated assessment tool to define effective air quality policies at regional scale," Environ. Model. Softw., vol. 38, pp. 306-315, Dec. 2012.
[32] A. Castelletti, S. Galelli, M. Ratto, R. Soncini-Sessa, and P. C. Young, "A general framework for dynamic emulation modelling in environmental problems," Environ. Model. Softw., vol. 34, pp. 5-18, Jun. 2012.

[33] D. Huppmann et al., "The MESSAGE integrated assessment model and the ix modeling platform (ixmp): An open framework for integrated and cross-cutting analysis of energy, climate, the environment, and sustainable development," Environ. Model. Softw., vol. 112, pp. 143-156, Feb. 2019.

[34] F. Zhao, Y. Fan, and S. Zhang, "Assessment of efficiency improvement and emission mitigation potentials in China's petroleum refining industry," J. Cleaner Prod., vol. 280, Jan. 2021, Art. no. 124482.

[35] S. Zhang, Y. Xie, R. Sander, H. Yue, and Y. Shu, "Potentials of energy efficiency improvement and energy-emission-health nexus in Jing-Jin-Ji's cement industry," J. Cleaner Prod., vol. 278, Jan. 2021, Art. no. 123335 .

[36] S. Zhang, H. Ren, W. Zhou, Y. Yu, and C. Chen, "Assessing air pollution abatement co-benefits of energy efficiency improvement in cement industry: A city level analysis," J. Cleaner Prod., vol. 185, pp. 761-771, Jun. 2018.

[37] X. Tian et al., "Economic impacts from PM2.5 pollution-related health effects in China's road transport sector: A provincial-level analysis," Environ. Int., vol. 115, pp. 220-229, Jun. 2018.

[38] H. Relvas, A. I. Miranda, C. Carnevale, G. Maffeis, E. Turrini, and M. Volta, "Optimal air quality policies and health: A multiobjective nonlinear approach," Environ. Sci. Pollut. Res., vol. 24, no. 15, pp. 13687-13699, May 2017

[39] C. Carnevale, E. D. Angelis, G. Finzi, E. Pisoni, E. Turrini, and M. Volta, "Coupling European data and local air pollution models for integrated assessment," IFAC-PapersOnLine, vol. 51, no. 5, pp. 67-72, 2018.

[40] A. I. Miranda et al., "Applying integrated assessment methodologies to air quality plans: Two European cases," Environ. Sci. Policy, vol. 65, pp. 29-38, Nov. 2016.

[41] C. Carnevale, G. Finzi, G. Guariso, E. Pisoni, and M. Volta, "Surrogate models to compute optimal air quality planning policies at a regional scale," Environ. Model. Softw., vol. 34, pp. 44-50, Jun. 2012.

[42] A. Marino, Analysis and Enumeration: Algorithms for Biological Graphs. Dordrecht, The Netherlands: Atlantis Publishing Corporation, 2015, pp. 1-151.

[43] European Commission. (2015). Clean Energy for All Europeans Package. [Online]. Available: https://ec.europa.eu/energy/en/topics/energystrategy/clean-energy-all-europeans

[44] Contesto ed Evoluzione del Sistema Elettrico, TERNA, Rome, Italy, 2019.

[45] Elettricità Nelle Regioni, TERNA, Rome, Italy, 2019.

[46] Rapporto Statistico 2018-Fonti Rinnovabili, Gestore dei Servizi Energetici, Rome, Italy, 2019.

[47] G. Riva, J. Calzoni, and A. Panvini, "Impianti a biomasse per la produzione di energia elettrica," Comitato Termotecnico Italiano-Energia e Ambiente, Milan, Italy, Tech. Rep., Dec. 2020.

[48] Regione Lombardia. (2020). Regione Lombardia-Open Data Aree urbanizzate. Accessed: Jun. 18, 2020. [Online]. Available: htp://www.dati.lombardia.it/Territorio/Aree-Urbanizzate/68nt-pud4

[49] T. Huld and I. Pinedo-Pascua. (2020). Phovoltaic Geographical Information System. [Online]. Available: https://ec.europa.eu/jrc/en/pvgis

[50] Althesys. (2018). L'Idroelettrico Crea Valore per L'ItaliaScenari e Proposte per Valorizzare il Patrimonio Idroelettrico Italiano. [Online]. Available: http://www.althesys.com/wp-content/ uploads/2018/06/Rassegna-stampa-Rilancio-idroelettrico-al-2018-0716.pdf

[51] Global EV Outlook 2019 to Electric Mobility, Int. Energy Agency, Paris, France, 2019.

[52] I. A. Raposo et al., The Future of Road Transport-Implications of Automated, Connected, Low-Carbon and Shared Mobility. Luxembourg City, Luxembourg: Publications Office of the European Union, 2019.

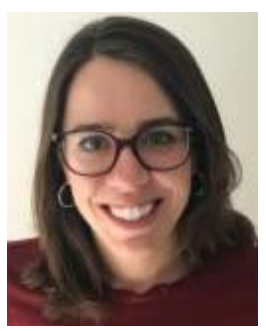

Elena De Angelis received the B.S. and M.S degrees in environmental and land planning engineering from the Politecnico of Milano, Milan, Italy, in 2014 and 2016, respectively. She is currently pursuing the Ph.D. degree in technology for health with the University of Brescia, Brescia, Italy.

Her research focuses on air quality integrated assessment modeling and the definition of air quality and climate change win-win policies. 


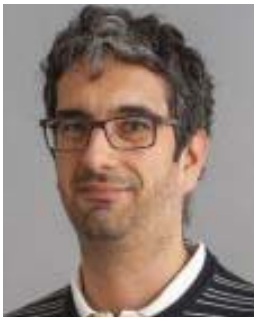

Claudio Carnevale (Member, IEEE) received the Laurea degree in electronic engineering and the Ph.D. degree in information engineering from the University of Brescia, Brescia, Italy, in 2001 and 2005, respectively.

$\mathrm{He}$ is an Associate Professor with the Department of Mechanical and Industrial Engineering, University of Brescia. His main research interests are modeling and control of deterministic nonlinear systems, online and offline data assimilation techniques for air quality applications, identification of nonlinear systems, and decisional models in multiobjective optimization problems.

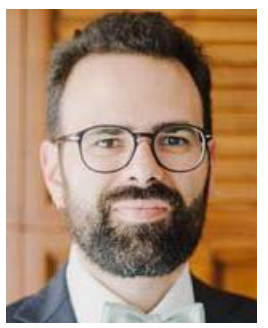

Gioele Di Marcoberardino received the B.S. degree in energy engineering from the University of Bologna, Bologna, Italy, in 2008, the M.S. degree in energy engineering and the Ph.D. degree in energy and nuclear science and technology from the Politecnico di Milano, Milan, Italy, in 2012 and 2015, respectively.

He is a Research Fellow with the Department of Mechanical and Industrial Engineering, University of Brescia, Brescia, Italy. His main research interests are energy systems modeling and thermal stability of working fluids for Organic Rankine Cycle (ORC) and other innovative cycle for power production.

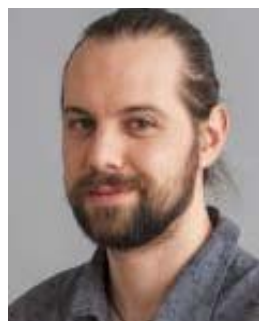

Enrico Turrini received the M.S. degree in environmental engineering and the Ph.D. degree from the University of Brescia, Brescia, Italy, in 2012 and 2016, respectively.

He is a Post-Doctoral Researcher with the Department of Mechanical and Industrial Engineering, University of Brescia. His main research interests are formalization and analysis of nonlinear decision models for planning and control of complex systems.

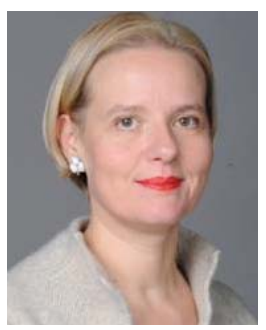

Marialuisa Volta (Member, IEEE) received the Laurea degree in electrical engineering from the Politecnico di Milano, Milan, Italy, in 1994, and the Ph.D. degree in information engineering from the University of Brescia, Brescia, Italy, in 1999.

She is a Full Professor of control systems with the Department of Mechanical and Industrial Engineering, University of Brescia. She has authored or coauthored more than 170 papers, book chapters, and books. She coordinated EU and national projects developing methodologies and tools for air quality control, involving research institutes, Small and medium-sized enterprises (SMEs), and decision-makers. Her research interests deal with nonlinear systems analysis, control systems design, environmental systems modeling and control, decision models, and integrated assessment modeling. 